\title{
PENGARUH SEMANGAT KERJA, LINGKUNGAN KERJA DAN KOMUNIKASI INTERPERSONAL TERHADAP PENGEMBANGAN KARIR KARYAWAN DINAS PERHUBUNGAN KOTA SURABAYA
}

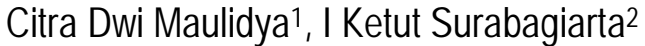 \\ Universitas PGRI Adi Buana Surabaya1,2 \\ citradwimaulidya@gmail.com
}

\begin{abstract}
ABSTRAK
Lokasi penelitian di Dinas Perhubungan Kota Surabaya dengan tujuan ingin mengetahui pengaruh variabel semangat kerja, lingkungan kerja, dan komunikasi interpersonal terhadap pengembangan karir karyawan Dinas Perhubungan Kota Surabaya baik parsial maupun simultan. Metode yang digunakan Dalam penelitian ini kuantitatif dengan sampel sebanyak 50 karyawan. Teknik yang digunakan dalam pengumpulan data memakai kuesioner dan dokumentasi dengan teknik pengambilan sampel purposive sampling. Dari hasil penelitian yang didapat secara pengujian parsial diketahui Variabel semangat kerja memperoleh nilai t-hitung 2,309 dan nilai signifikan 0,025 $(0,025 \leq 0,05)$. Variabel lingkungan kerja memperoleh nilai t-hitung untuk 2,506 dan nilai signifikan $0,016(0,016 \leq 0,05)$. Variabel komunikasi Interpersonal memperoleh nilai thitung 2,168 dan nilai signifikan $0,035(0,035 \geq 0,05$. Dalam pengujian simultan diperoleh nilai f-hitung 16,385 dan nilai signifikan $0,000(0,000 \leq 0,05)$. Sehingga dapat dinyatakan jika terdapat pengaruh yang signifikan dari semangat kerja lingkungan kerja dan komunikasi interpersonal terhadap pengembangan kairir baik secara uji parsial atau uji simultan.
\end{abstract}

Kata kunci: semangat kerja, lingkungan kerja, komunikasi interpersonal, pengembangan karir.

\begin{abstract}
The research location in Surabaya City Transportation Department with the aim of wanting to find out the influence of work morale, work environment, and interpersonal communication variables on the career development of Surabaya City Transportation Department employees, both partial and simultaneous. The method used in this research is quantitative with a sample of 50 employees. The technique used in data collection uses a questionnaire and documentation with a purposive sampling technique. From the research results obtained by partial testing it is known that the morale variable obtained a t-count value of 2.309 and a significant value of $0.025(0.025 \leq 0.05)$. The work environment variable obtained a $t$-count value for 2.506 and a significant value of $0.016(0.016 \leq 0.05)$. Interpersonal communication variable obtained a $t$-count value of 2.168 and a significant value of $0.035(0.035 \geq 0.05$. In the simultaneous test obtained $f$-count value of 16.338 and a significant value of $0.000(0.000 \leq 0.05)$. So it can be stated if there is a significant influence of working spirit of the work environment and interpersonal communication towards the development of the department either through partial or simultaneous tests.
\end{abstract}

Keywords: work spirit, work environment, interpersonal communication, career development. 
Vol. 1 No. 1 Desember 2020

\section{PENDAHULUAN}

Semakin disadari, persoalan pembangunan tak hanya melulu persoalan infrastruktur, peningkatan SDM semakin urgen. Peningkatan kualitas SDM masih terus diperjuangkan. Bagaimanapun, kualitas SDM menjadi pintu masuk utama dalam upaya peningkatan daya saing. Bagi suatu perusahaan atau organisasi, SDM memiliki peran penting untuk penentu keberhasilan dalam menjalankan suatu kegiatan. SDM yang berkualitas akan menghasilkan knerja yang berkualiatas pula dalam menyelesaikan tugas-tugas yang diberikan sehingga tujuan perusahaan akan tercapai.

Dalam sebuah perusahaan pengembangan karir sangat penting karena dengan melakukan pengembangan diri dapat membuat sebuah perusahaan semakin maju di era globalisasi saat ini. Dengan malakukan pengembangan karir akan membuat kemampuan yang dimiliki para karyawan perusahaan semakin bertambah dan berkembang dalam mengerjakan pekerjaan, sehingga akan menyebabkan citra dan karir dalam suatu perusahaan akan naik. Dengan begitu tujuan perusahan maupun tujuan yang dimiliki oleh karyawan akan tercapai.

Untuk mengembangkan karir, dibutuhkan semangat kerja dari para karyawan agar memiliki moral kerja yang tinggi dalam bekerja. Dengan begitu dapat membuat semangat yang dimiliki karyawan akan meningkat sehingga para karyawan dapat mengembangkan karir dengan maksimal.

Salah satu faktor untuk mengembangkan karir pada karyawan, perusahaan juga harus memperhatikan lingkungan kerja karena akan berpengaruh pada para karyawan saat bekerja. Jika lingkungan perusahaan nyaman akan membuat para karyawan bekerja dengan sebaik mungkin dan semaksimal mungkin dalam mengerjakan tugas yang telah diberikan perusahaan dengan harapan mendorong para karyawan untuk mengembangkan diri dengan maksimal.

Selain semangat kerja dan lingkungan kerja, komunikasi juga mempunyai peran yang besar di dalam sebuah organisasi atau perusahaan karena komunikasi merupakan aktivitas dasar manusia. Komunikasi yang terjadi dua orang atau lebih secara langsung disebut dengan komunikasi interpersonal.

Dalam pengembangan karir, komunikasi interpersonal sangat diperlukan untuk berkomunikasi dengan pimpinan atau para karyawan dalam suatu perusahaan, hal ini berlaku untuk efektivitas organisasi agar tercipta iklim organisasi yang baik sehingga para karyawan mampu mengembangkan diri dengan maksimal agar perusahaan semakin maju dan tujuan perusahaan dapat tercapai.

Semangat kerja, lingkungan kerja, dan komunikasi interpersonal sangat bersinambungan dengan pengembangan karir. karena 3 variabel tersebut hal yang mendasar bagi suatu perusahaan atau organisasi untuk meningkatkan pengembangan karir para karyawan agar perusahaan menjadi lebih maju dan tujuan suatu perusahaan tercapai.

Ruang lingkup dalam penelitian ini merupakan karyawan dari Dinas Perhubungan Kota Surabaya dengan jumlah responden sebesar 50 karyawan.

Dari uraian diatas, maka peneliti ingin mengetahui bagaimana hubungan Semangat Kerja, Lingkungan Kerja dan Komunikasi Interpersonal Terhadap Pengembangan Karir Karyawan Dinas Perhubungan Kota Surabaya.

Dari latar belakang tersebut, maka peneliti dapat membuat rumusan masalah yaitu:

a. Apakah semangat kerja berpengaruh terhadap pengembangan karir karyawan Dinas Perhubungan Kota Surabaya? 


\section{Vol. 1 No. 1 Desember 2020}

b. Apakah lingkungan kerja berpengaruh terhadap pengembangan karir karyawan Dinas Perhubungan Kota Surabaya?

c. Apakah komunikasi interpersonal berpengaruh terhadap pengembangan karir karyawan Dinas Perhubungan Kota Surabaya?

d. Apakah semangat kerja, lingkungan kerja dan komunikasi interpersonal berpengaruh terhadap pengembangan karir karyawan Dinas Perhubungan Kota Surabaya?

Dari rumusan masalah tersebut, terdapat tujuan penelitian yang sejalan dengan rumusan masalah yaitu untuk mengetahui dan menganalisis dari setiap variabel penelitian baik secara parsial maupun simultan.

\section{TINJAUAN PUSTAKA DAN HIPOTESIS}

\section{Tinjauan Pustaka}

Bagi suatu perusahaan atau organisasi SDM memiliki peran penting untuk penentu keberhasilan dalam menjalankan suatu kegiatan. SDM yang berkualitas akan menghasilkan knerja yang berkualiatas pula dalam menyelesaikan tugas-tugas yang diberikan sehingga tujuan perusahaan akan tercapai.

Kasmir (2018:6) berpendapat manajemen sumber daya manusia adalah proses pengelolaan manusia dengan melakukan perencanaan, pengorganisasia, pengembangan dan pelatihan guna mencapai tujuan suatu perusahaan atau organisasi.

Menurut Nitisemito (2018:160) Semangat kerja didefinisikan dengan tindakan malakukan suatu pekerjaan dengan giat dan cepat dalam sebuah perusahaan yang dilakukan oleh para karyawan guna untuk meningkatkan kinerja dalam mencapai tujuan suatu perusahaan atau organisasi.

Lingkungan kerja menurut Nitisemito (2018:183) diartikan sebagai kehidupan sosial karyawan di perusahaan yang dapat memengaruhi karyawan dalam mengerjakan tugas yang telah diberikan perusahaan.

Devito (2011:252) berpendapat komunikasi interpersonal adalah komunikasi yang dilakukan oleh dua orang atau lebih dalam suatu masyarakat atau perusahaan yang setiap orangnya menangkap reaksi orang lain secara langsung.

Pengembangan karir menurut Handoko (2014:123) dapat diartikan kegiatan-kegiatan dalam mengembangkan kemampuan yang dimiliki para karyawan dalam suatu perusahaan dengan harapan memiliki jabatan yang lebih baik dimasa yang mendatang.

\section{Kerangka Konseptual}

Dalam perusahaan pengembangan karir sangat penting karena dengan melakukan pengembangan diri dapat membuat sebuah perusahaan semakin maju di era globalisasi saat ini. Pengembangan karir digunakan untuk mengembangkan kemampuan para karyawan sehingga kemampuan yang dimiliki para karyawan semakin bertambah dan berkembang dalam mengerjakan pekerjaan, sehingga akan menyebabkan citra dan karir dalam suatu perusahaan akan naik.

\section{Hipotesis}

Berdasarkan perumusan masalah tersebut terdapat hipotesis, yaitu:

1. Semangat kerja berpengaruh terhadap Pengembangan Karir karyawan Dinas Perhubungan Kota Surabaya. 
Vol. 1 No. 1 Desember 2020

2. Lingkungan kerja berpengaruh terhadap Pengembangan Karir karyawan Dinas Perhubungan Kota Surabaya.

3. Komunikasi interpersonal berpengaruh terhadap Pengembangan Karir karyawan Dinas Perhubungan Kota Surabaya.

4. Semangat kerja, lingkungan kerja, dan komunikasi interpersonal berpengaruh terhadap Pengembangan Karir karyawan Dinas Perhubungan Kota Surabaya.

\section{METODE}

Lokasi Penelitian di Dinas Perhubungan Kota Surabaya dengan memakai metode penelitian kuantitatif. Populasi penelitian ini dari karyawan Dinas Perhubungan Kota Surabaya sendiri dengan sampel sebanyak 50 karyawan tetap dengan melakukan penyebaran kuesioner dan melakukan dokumentasi. Pengambilan sampel memakai purposive sampling. Teknik analisis data melakukan berbagai pengujian meliputi: pengujian asumsi klasik, analisis regresi linier berganda, pengujian hipotesis meliputi uji t dan uji f. Sedangkan pengolahan data dengan memakai program SPSS 24.

\section{HASIL}

\section{Karakteristik Responden}

Tabel ini berisikan karakteristik data dari para responden.

Tabel 1 Karakteristik Responden

\begin{tabular}{|l|l|l|}
\hline \multicolumn{1}{|c|}{ Jenis kelamin } & \multicolumn{1}{c|}{ Jumlah } & \multicolumn{1}{c|}{ Presentase } \\
\hline Laki-laki & 29 & $58 \%$ \\
\hline Perempuan & 21 & $42 \%$ \\
\hline Total & 50 & $100 \%$ \\
\hline \multicolumn{1}{|c|}{ Usia } & \multicolumn{1}{|c|}{ Jumlah } & Presentase \\
\hline 21 s/d 30 Tahun & 22 & $44 \%$ \\
\hline 31 s/d 40 Tahun & 10 & $20 \%$ \\
\hline 41 s/d 50 Tahun & 15 & $30 \%$ \\
\hline 51 s/d 60 Tahun & 3 & $6 \%$ \\
\hline Total & 50 & $100 \%$ \\
\hline \multicolumn{1}{|c|}{ Pendidikan } & \multicolumn{1}{c|}{ Jumlah } & Presentase \\
\hline SMA & 25 & $50 \%$ \\
\hline D3 & 3 & $6 \%$ \\
\hline D4 & 4 & $8 \%$ \\
\hline S1 & 18 & $36 \%$ \\
\hline Total & 50 & $100 \%$ \\
\hline
\end{tabular}




\section{7}

Vol. 1 No. 1 Desember 2020

\section{Hasil Uji Instrumen Penelitian}

\section{a. Uji Validitas}

Dari hasil pengujian validitas yang didapatkan mengenai setiap variabel penelitian, diketahui variabel semangat kerja, lingkungan kerja, komunkasi interpersonal dan pengembangang karir memperoleh item pernyataan dari setiap indikator yang nilai signifikan $(<0,05)$ jadi keseluruhan pernyataan yang dipakai dalam penelitian ini dinyatakan valid.

\section{b. Uji Reliabilitas}

Berikut ini adalah hasil dari pengujian reliabilitas:

Tabel 2 Uji Reliabilitas

\begin{tabular}{|l|c|}
\hline \multicolumn{1}{|c|}{ Variabel } & Koefisien Alpha \\
\hline Semangat Kerja & 0,893 \\
\hline Lingkungan Kerja & 0,894 \\
\hline $\begin{array}{l}\text { Komunikasi } \\
\text { Interpersonal }\end{array}$ & 0,909 \\
\hline Pengembangan Karir & 0,903 \\
\hline
\end{tabular}

Dari tabel diatas dapat disumpulkan bahwa nilai koefisien reliabilitas cronbach's alpha $>0,60$, sehingga dapat dinyatakan jika kueisoner dalam penelitian ini sangat reliabel.

\section{Hasil Asumsi Klasik}

\section{a. Uji Normalitas}

Berdasarkan pengujian uji kolmogrov-smirnov yang dilakukan, didapat nilai asymp.sig $0,056(>0,05)$, sehingga dapat dikatakan jika data yamg digunakan untuk penelitian berdistribusi normal.

\section{b. Uji Multikolinearitas}

Berdasarkan hasil pengujian yang didapatkan, menyatakan bahwa dari setiap variabel bebas digunakan mendapatkan nilai VIF $\geq 10$ dan mendapatkan nilai toleransi $\leq 0,10$, sehingga ; dikatakan bebas dari multikolinearitas.

Tabel 3 Uji Multikolinearitas

\begin{tabular}{|l|l|l|l|}
\hline \multirow{2}{*}{ Variabel Independen } & \multicolumn{2}{|l|}{ Collinearity Statistics } & \multirow{2}{*}{ Keterangan } \\
\cline { 2 - 4 } & Tolaerance & VIF & \\
\hline Semangat Kerja & 0,523 & 1,911 & Non Multikolineaitas \\
\hline Lingkungan Kerja & 0,532 & 1,880 & Non Multikolineaitas \\
\hline Komunikasi Interpersonal & 0,930 & 1,075 & Non Multikolineaitas \\
\hline
\end{tabular}

\section{c. Uji Heteroskedastisitas}

Berdasarkan hasil pengujian dengan menggunakan pola scatterplot, didapatkan hasil scatterplot memiliki pola yang tidak beraturan dan bintik-bintik pada gambar scatterplot memencar dengan acak di atas dan di bawah angka 0 pada sumbu $Y$ sehingga dapat dikatakan tidak ada gejala heteroskedastisitas. 


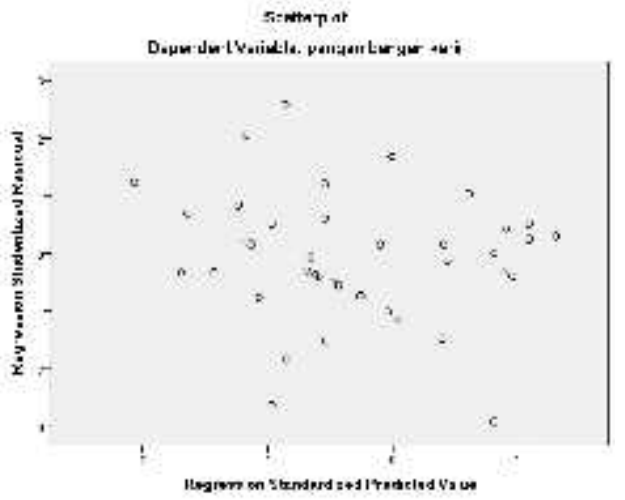

Gambar 1 Uji Heteroskedastisitas

\section{d. Uji Autokorelasi}

Berdasarkan pengujian uji autokorelasi didapat nilai DW (Durbin-Watson) 1,887 (berada diantara 1,674-2,326), maka dapat dinyatakan regresi berganda yang digunakan tidak terdapat autokorelasi.

\section{Uji Analisis Regresi Linier Berganda}

Berikut ini hasil penelitian yang di dapat dari uji analisis regresi linier berganda:

Tabel 4 Analisis Regresi Linier Berganda

\begin{tabular}{|l|l|l|l|l|l|}
\hline \multirow{2}{*}{ Model } & \multicolumn{2}{|l|}{ Unstandardized Coefficients } & Standardized Coefficients & \multirow{2}{*}{ t } & Sig. \\
\cline { 2 - 6 } & $\mathbf{B}$ & Std. Error & Beta & .092 & .927 \\
\hline (Constant) & .634 & 6.856 & & 2.309 & .025 \\
\hline Semangat Kerja $(\mathrm{X} 1)$ & .477 & .207 & .327 & 2.506 & .016 \\
\hline Lingkungan Kerja $(\mathrm{X} 2)$ & .520 & .207 & .352 & 2.168 & .035 \\
\hline Komunikasi Interpersonal $(\mathrm{X} 3)$ & .271 & .125 & .230 &
\end{tabular}

Berdasarkan pengujian analisis regresi linier berganda diketahui nilai keterpengaruhan antara dari setiap variabel, yaitu:

$$
Y=0,634+0,477 \times 1+0,520 \times 2+0,271 \times 3+e
$$

Berdasarkan hasil persamaan yang di dapat maka dapat dijelaskan bahwa:

a. nilai konstanta yang didapatkan 0,634 . Dapat dikatakan jika nilai dari variabel semangat kerja, lingkungan kerja, dan komunikasi interpersonal sama dengan nol. Jadi nilai variabel pengembangan karir yaitu 0,634 .

b. Koefisien regresi dari semangat kerja memperoleh nilai 0,477 , hal ini dapat dikatakan jika besarnya pengaruh semangat kerja terhadap pengembangan karir, koefisien regresi yang didapatkan bernilai positif yang berarti semangat kerja berpengaruh secara sejalan terhadap pengembangan karir, yang artinya setiap peningkatan dari nilai variabel semangat kerja satu satuan maka akan membuat peningkatan pengembangan karir sebesar 0,477 satuan.

c. Koefisien regresi dari lingkungan kerja mendapatkan nilai 0,520 , hal ini dapat dikatakan jika besarnya pengaruh dari variabel lingkungan kerja terhadap pengembangan karir, koefisien regresi yang didapatkan bernilai positif yang berarti lingkungan kerja berpengaruh secara 


\section{Vol. 1 No. 1 Desember 2020}

sejalan terhadap pengembangan karir, yang artinya setiap peningkatan dari nilai variabel lingkungan kerja satu satuan maka akan membuat peningkatan pengembangan karir sebesar 0,520 satuan.

d. Koefisien regresi dari variabel komunikasi interpersonal memperoleh nilai 0,271 , hal ini dapat dikatakan jika besarnya pengaruh komunikasi interpersonal terhadap variabel pengembangan karir, koefisien regresi yang didapatkan bernilai positif yang berarti komunikasi interpersonal berpengaruh secara sejalan terhadap variabel pengembangan karir, yang artinya setiap peningkatan dari nilai variabel komunikasi interpersonal satu satuan maka akan membuat peningkatan pengembangan karir sebesar 0,271 satuan.

\section{Pengujian Hipotesis}

\section{a. Uji t (Parsial)}

Dari hasil pengujian uji t pada tabel 4, didapatkan hasil dari setiap hipotesis, yaitu:

\section{Hipotesis 1}

Dari hasil pengujian uji t, nilai t-hitung pada variabel semangat kerja 2,309 dengan nilai signifikan $0,025(0,025 \leq 0,05)$. Jadi semangat kerja berpengaruh signifikan terhadap pengembangan karir.

2. Hipotesis 2

Dari hasil pengujian uji t, nilai t-hitung pada variabel lingkungan kerja 2,506 dengan nilai signifikan sebesar $0,016(0,016 \leq 0,05)$. Jadi lingkungan kerja berpengaruh signifikan terhadap pengembangan karir.

3. Hipotesis 3

Dari hasil pengujian uji t, nilai t-hitung pada komunikasi interpersonal 2,168 dengan nilai signifikan $0,035(0,035 \leq 0,05)$. Jadi komunikasi interpersonal berpengaruh signifikan terhadap pengembangan karir.

\section{b. Uji f (Simultan)}

Dari hasil pengujian uji f, nilai f-hitung 16,385 dengan nilai signifikan $0,000(0,000 \leq$ 0,05). Jadi semangat kerja, lingkungan kerja dan komunikasi interpersonal berpengaruh signifikan terhadap variabel pengembangan karir.

\section{SIMPULAN}

Dari hasil analisis data regresi linier berganda memakai program SPSS versi 24 dan dari hasil pembahasan yang di uraikan, maka di ambil simpulan dari hasil penelitian mengenai judul "semangat kerja, lingkungan kerja dan komunikasi interpersonal berpengaruh terhadap pengembangan karir karyawan Dinas Perhubungan Kota Surabaya, yaitu:

1. Keterpengaruhan yang signifikan pada variabel Semangat kerja terhadap pengembangan karir karyawan Dinas Perhubungan Kota Surabaya dengan pengujian uji t didapat nilai t-hitung dari variabel semangat kerja 2,309 dan nilai signifikan $0,025(0,025 \leq 0,05)$.

2. Keterpengaruhan yang signifikan pada variabel lingkungan kerja terhadap pengembangan karir karyawan Dinas Perhubungan Kota Surabaya dengan pengujian uji t didapat nilai t-hitung dari variabel lingkungan kerja 2,506 dan nilai signifikan 0,016 $(0,016 \leq 0,05)$.

3. Keterpengaruhan yang signifikan pada variabel Komunikasi interpersonal terhadap pengembangan karir karyawan Dinas Perhubungan Kota Surabaya dengan pengujian uji $t$ 


\section{Vol. 1 No. 1 Desember 2020}

didapat nilai t-hitung dari variabel komunikasi interpersonal 2,168 dan nilai signifikan $0,035(0,035$ $\geq 0,05$ ).

4. Berdasarkan pengujian yang telah dilakukan menggunakan uji-f maka bisa disimpulkan jika ada keterpengaruhan yang signifikan pada variabel Semangat kerja, Lingkungan kerja, dan Komunikasi interpersonal terhadap pengembangan karir karyawan Dinas Perhubungan Kota Surabaya dengan memperoleh nilai f-hitung 16,385 dan nilai signifikan $0,000(0,000 \leq 0,05)$.

\section{IMPLIKASI}

Bagi suatu perusahaan atau organisasi SDM memiliki peran penting untuk penentu keberhasilan dalam menjalankan suatu kegiatan. Di era globalisasi yang semaikin maju ini, perusahaan dituntut untuk melakukan pengembangan diri. Dengan malakukan pengembangan karir akan membuat kemampuan yang dimiliki para karyawan perusahaan semakin bertambah dan berkembang dalam mengerjakan pekerjaan, sehingga akan menyebabkan citra dan karir dalam suatu perusahaan akan naik. Dari hasil penelitian di dapat dan simpulan yang diuraikan di atas, maka dapat dikemukakan implikasi, yaitu:

1. Meningkatkan semangat kerja dari para karyawan agar memiliki moral kerja yang tinggi dalam bekerja dengan begitu dapat membuat semangat yang dimiliki karyawan akan meningkat sehingga para karyawan dapat mengembangkan karir dengan maksimal.

2. Perusahaan harus memperhatikan lingkungan kerja. Lingkungan kerja juga mempengaruhi para karyawan dalam bekerja. Jika lingkungan perusahaan nyaman akan membuat para karyawan bekerja dengan sebaik mungkin dan semaksimal mungkin dalam mengerjakan tugas yang telah diberikan perusahaan dengan harapan mendorong para karyawan untuk mengembangkan diri dengan maksimal.

3. Komunikasi interpersonal sangat diperlukan untuk berkomunikasi dengan pimpinan atau para karyawan dalam suatu perusahaan. Hal ini berlaku untuk efektivitas organisasi agar tercipta iklim organisasi yang baik sehingga para karyawan mampu mengembangkan diri dengan maksimal.

\section{KETERBATASAN PENELITIAN}

1. Tidak dapat mengambil sampel lebih dari 50 responden karena Dinas Perhubungan Kota Surabaya hanya membatasi penyebaran kuesioner sebanyak 50.

2. Responden dalam memberikan jawaban terkadang tidak menunjukkan keadaan yang sebenarnya di dalam perusahan.

\section{DAFTAR RUJUKAN}

Awaludin Fikri, 2017, Pengaruh pengembangan karir, motivasi kerja, dan gaya kepemimpinan terhadap semanga kerja pegawai PT. PLN (persero) Kota Kediri, Universitas Nusantara PGRI Kediri.

Handoko, T Hani, 2014, Manajemen Personalia dan Sumber daya Manusia, BPFE, Yogyakarta.

Latifah, 2017, pengaruh efektifitas komunikasi dan desain pekerjaan terhadap pengembangan karir karyawan PT. Puji Surya Indah di Surabaya, Universitas Adi Buana Surabaya.

Musaroraf, Juliatin, 2016, persepsi pengembangan karir dan lingkungan kerja terhadap kepuasan kerja karyawan CV. Utama Jaya, Universitas Adi Buana Surabaya.

Nitisemito, Alex S, 2016, Manajemen Personalia (manajemene sumber daya manusia), cetakan ke 6. Jakarta. Ghalia Indonesia. 


\section{7}

Vol. 1 No. 1 Desember 2020

Pamungkur, 2016, pengaruh komunikasi, lingkungan kerja, pengembangan karyawan dan motivasi terhadap semangat kerja karyawan PT. PLN Cabang Palangka Raya, STIE Palangka Raya.

Sedarmayanti, 2017, Manajemen Sumber Daya Manusia, PT. Refika Aditama, Bandung. 